\title{
Comment on "The Effect of Hyperbaric Oxygen Therapy on Rectal Ulcers after Argon Plasma Coagulation"
}

\author{
João A. Cunha Neves ${ }^{a}$ Joana Roseira ${ }^{a}$ Patrícia Queirós $^{a}$ \\ Helena Tavares de Sousa $a^{a, b}$ \\ ${ }^{a}$ Gastroenterology Department, Centro Hospitalar Universitário do Algarve, Portimão, Portugal; ${ }^{b}$ Department of \\ Biomedical Sciences and Medicine, University of Algarve, Faro, Portugal
}

\section{Keywords}

Argon plasma coagulation therapy $\cdot$ Hyperbaric oxygen therapy · Chronic radiation proctitis · Radiation-induced rectal ulcers · Alternative therapy

\section{Comentário a "O papel da oxigenoterapia hiperbárica nas úlceras retais secundárias à terapêutica com árgon-plasma"}

\section{Palavras Chave}

Terapêutica com árgon-plasma · Oxigenoterapia hiperbárica · Proctite rádica crónica - Úlceras retais induzidas por radiação · Terapêutica alternativa

\section{Dear Editor,}

We read with great interest the paper by Laranjo et al. [1] entitled "The Effect of Hyperbaric Oxygen Therapy on Rectal Ulcers after Argon Plasma Coagulation." The authors reported the case of a patient with chronic radiation proctitis, who developed rectal ulcers after endoscopic treatment with argon plasma coagulation (APC) and was successfully treated with hyperbaric oxygen therapy $(\mathrm{HBO})$. Although it is well established that $\mathrm{HBO}$ therapy is an effective alternative treatment for patients with radiation-induced rectal ulcers and severe chronic proctitis $[2,3]$, its application has not been described as a treatment option in APC-induced rectal ulcers. We acknowledge the authors' awareness of $\mathrm{HBO}$ as an option for complications induced by conventional chronic proctitis treatments and we would like to share our experience on this particular matter. A 72-year-old female patient was admitted to our Emergency Department with rectal bleeding, acute anal pain, and iron deficiency anemia (hemoglobin $10.7 \mathrm{~g} / \mathrm{dL}$ ). She had a past medical history of endometrial carcinoma treated with radio- and brachytherapy 2 years before. Total colonoscopy revealed multiple bleeding rectal radiation-induced telangiectasias. Medical treatment with topical salicylates and sucralfate for 8 months was unsuccessful and APC therapy ( $45 \mathrm{~W}$; $1.5 \mathrm{~L} / \mathrm{min}$ gas flow) every 4 weeks was initiated. The patient was submitted to a total of 6 APC sessions, with an overall endoscopic improvement between the first and third sessions. However, amidst the fourth and sixth APC sessions, the patient developed multiple APC-induced ulcers and an ulcerated stenosis of the distal rectum. After

\section{(c) 2021 Sociedade Portuguesa de Gastrenterologia.} Published by S. Karger AG, Basel

This is an Open Access article licensed under the Creative Common Attribution-NonCommercial-4.0 International License (CC BY-NC) (http://www.karger.com/Services/OpenAccessLicense), applicable to the online version of the article only. Usage and distribution for commercial purposes requires written permission.
Correspondence to:

João António Cunha Neves, joaoacunhaneves@gmail.com 
6 months of treatment, her symptoms remained with sigmoidoscopy revealing the persistence of bleeding telangiectasias and a progressive worsening of the endoscopic appearance. The patient then underwent 30 sessions of HBO therapy, over a period of 7 months, with full symptomatic resolution and healing of the rectal ulcer. At 1 year of follow-up, the patient remained asymptomatic.

Rectal ulcerations arise after APC treatment in about half of the cases [4]. This high percentage may be caused by the frailty and poor healing of the mucosa due to thermal injury, among other factors [4]. Furthermore, Laranjo et al. [1] focus on an important aspect of the APC technique itself. The lack of guidelines for the optimal APC settings (method of application, time between sessions, and flow rate) may lead to a higher number of APC-induced ulcers. According to Sato et al. [5] prevention of damage of the deeper underlying muscle layer, while maintaining an effective submucosal telangiectasia treatment, occurs with the lowest effective dose of $40 \mathrm{~W}$ with $1.2 \mathrm{~L} / \mathrm{min}$ of gas flow and a coagulation time of $2 \mathrm{~s}$. In both our case and that of Laranjo et al. [1], the dose and flow applied were adequate, but the time of coagulation was not taken into consideration. The latter may have been the culprit for the development of the APC-induced ulcers.

Both patients were successfully treated with $\mathrm{HBO}$ therapy. Despite several trials and reports $[2,6,7]$ of its efficacy in radiation-induced rectal ulcers and severe chronic proctitis, there is still no formal guideline of $\mathrm{HBO}$ ther- apy for the treatment of APC-induced ulcers. Hence, these 2 case reports illustrate the urgent need for establishing universal settings for APC and of defining HBO therapy as an alternative treatment regimen for refractory APC-induced rectal ulcers.

\section{Statement of Ethics}

Informed consent was obtained from the patient for the case publication.

\section{Conflict of Interest Statement}

The authors have no conflicts of interest to declare.

Funding Sources

The authors have no funding sources to declare.

\section{Author Contributions}

João A. Cunha Neves wrote and edited the manuscript, approved the final manuscript, and is the article guarantor. Joana Roseira, Patrícia Queirós, and Helena Tavares de Sousa edited the manuscript, revised the manuscript for intellectual content, and approved the final manuscript.

\section{References}

1 Laranjo A, Carvalho M, Rei A, Veloso N, Medeiros I. The effect of hyperbaric oxygen therapy on rectal ulcers after argon plasma coagulation. GE Port J Gastroenterol. 2021;28:288-91.

2 Yoshimizu S, Chino A, Miyamoto Y, Tagao F, Iwasaki S, Ide D, et al. Efficacy of hyperbaric oxygen therapy in patients with radiation-induced rectal ulcers: report of five cases. Dig Endosc. 2017 Sep;29(6):718-22.

3 Weiner JP, Wong AT, Schwartz D, Martinez M, Aytaman A, Schreiber D. Endoscopic and non-endoscopic approaches for the management of radiation-induced rectal bleeding.
WorldJGastroenterol.2016Aug;22(31):697286.

4 Ravizza D, Fiori G, Trovato C, Crosta C. Frequency and outcomes of rectal ulcers during argon plasma coagulation for chronic radiation-induced proctopathy. Gastrointest Endosc. 2003 Apr;57(4):519-25.

5 Sato Y, Takayama T, Sagawa T, Hirakawa M, Ohnuma H, Miyanishi K, et al. Argon plasma coagulation treatment of hemorrhagic radiation proctopathy: the optimal settings for application and long-term outcome. Gastrointest Endosc. 2011 Mar;73(3):543-9.
6 Clarke RE, Tenorio LM, Hussey JR, Toklu AS Cone DL, Hinojosa JG, et al. Hyperbaric oxygen treatment of chronic refractory radiation proctitis: a randomized and controlled double-blind crossover trial with long-term follow-up. Int J Radiat Oncol Biol Phys. 2008 Sep;72(1):134-43.

7 Feldmeier JJ, Hampson NB. A systematic review of the literature reporting the application of hyperbaric oxygen prevention and treatment of delayed radiation injuries: an evidence based approach. Undersea Hyperb Med. 2002;29(1):4-30. 